\title{
New Trends in Modern Translation Studies \\ Review of Mishkurov E.N., 2018. "Hermeneutics of Translation" (Theoretical and Methodological Standard). Moscow, 299 p.
}

\author{
Marina G. Novikova \\ Russian State University of Justice \\ 69, Novocheremushkinskaya str., Moscow, 117418, Russia
}

\begin{abstract}
The article provides a review of E. Mishkurov's monograph "Hermeneutics of Translation" (Theoretical and Methodological Standard). Attention is drawn to the introduction to scientific use and a comprehensive analysis of the concept of "hermeneutic translation paradigm", which is based on the hermeneutic-translation methodological standard. It is illustrated that this standard reveals the essence of the translation process and includes four interrelated and complementary stages: pre-understanding, understanding, interpretation and the stage of making a translation decision. The advantages and perspectives of the hermeneutic translation paradigm over existing methodologies in modern translation studies are proved.

Keywords: hermeneutic translation paradigm, hermeneutic-translation methodological standard, pre-understanding, understanding, interpretation, translation decision

For citation:

Novikova, Marina (2019). New Trends in Modern Translation Studies. Review of Mishkurov E.N., 2018. "Hermeneutics of Translation" (Theoretical and Methodological Standard). Moscow, $299 \mathrm{p}$. Russian Journal of Linguistics, 23 (2), 562 - 568. doi: 10.22363/2312-9182-2019-23-2-562-568.
\end{abstract}

\section{Новые тенденции в современном переводоведении}

\section{Рецензия на монографию: Мишкуров Э.Н. «Герменевтика перевода» (теоретико-методологический стандарт) Москва: Военный университет, 2018. 299 с.}

\section{М.Г. Новикова}

Российский государственный университет правосудия ул. Новочеремушкинская, 69, 117418, Москва, Россия

\begin{abstract}
Аннотация
В статье дается рецензия на монографию Э.Н. Мишкурова «Герменевтика перевода» (теоретико-методологический стандарт). Обращается внимание на введение в научный обиход и всесторонний анализ понятия «герменевтическая парадигма перевода», которое базируется на герменев-
\end{abstract}


тико-переводческом методологическом стандарте. Показывается, что данный стандарт позволяет раскрыть сущность процесса перевода и включает в себя четыре взаимосвязанных и взаимодополняющих этапа: предпонимание, понимание, интерпретация и этап принятия переводческого решения. Доказываются преимущества и перспективность герменевтической парадигмы перевода перед существующими методологиями в современном переводоведении.

Ключевые слова: герменевтическая парадигма перевода, герменевтико-переводческий методологический стандарт, предпонимание, понимание, интерпретация, переводческое решение

\section{Для цитирования:}

Новикова М.Г. Новые тенденции в современном переводоведении. Рецензия на монографию: Мишкуров Э.Н. «Герменевтика перевода» (теоретико-методологический стандарт). Москва: Военный институт, 2018. 299 с. // Вестник Российского университета дружбы народов. Серия: Лингвистика $=$ Russian Journal of Linguistics. 2019. Т. 23. No 2. С. 562—568. doi: 10.22363/23129182-2019-23-2-562-568.

Характеризуя состояние современной транслатологии, следует отметить, что в исследованиях отечественных и зарубежных авторов не существует единства относительно ведущей парадигмы исследования. Актуальными являются как системно-структурная, так и антропоцентрическая, как семиотическая, так и когнитивно-дискурсивная парадигмы, что свидетельствует о необходимости разностороннего подхода к проблемам переводоведения. Если один «язык представляет собой сложный интегральный феномен и его изучение должно проходить в широком системном контексте» (Хомутова 2009: 148), то в ситуации, когда задействована пара или более рабочих языков, объект исследования настолько усложняется, что его успешное рассмотрение возможно исключительно с вовлечением не только лингвистической методологии, но и данных других наук.

Подобной системообразующей парадигмой является герменевтическая парадигма перевода, впервые введенная в научный обиход Эдуардом Николаевичем Мишкуровым и подробно рассмотренная им в рецензируемой монографии «Герменевтика перевода (теоретико-методологический стандарт)».

Автор определяет герменевтическую парадигму как «открытую синтезирующую систему, в которой находят свое место практически все значимые классические и инновационные модели перевода, отвечающие запросам рефлексирующего понимания, феноменологической редукции и оптимальной интерпретации рабочих текстов, а так же задачам принимаемых переводческих решений по перевыражению и перепорождению искомых «переводческих (переводных) закономерных соответствий и несоответствий» (Мишкуров 2018: 140).

Как видим, понятие «парадигма» не изменяет в монографии ученого своего изначального, предложенного Т. Куном смысла: «признанного всеми научного достижения, которое в течение определенного времени даст научному сообществу модель постановки проблем и их решений» (Кун 1977: 11), однако значительно расширяет свои понятийные границы.

Во-первых, синтезирующая система заключает в себе не одну - наиболее востребованную на данном историческом этапе развития модель постановки проблем и их решений, а все основные существующие и признанные научным сообществом (например, теорию закономерных соответствий Я.И. Рецкера (Рецкер 2016); теорию уровней эквивалентностей В.Н. Комиссарова (Комиссаров 1990); теорию функционально-динамической эквивалентности А.И. Швейцера (Швейцер 
1988); динамическую модель перевода Ю. Найды (Nida 1964), лингвоментальную модель перевода Т.А. Фесенко (Фесенко 2001), теорию полисистемы Эвен-Зохара (Even-Zohar 1990) и т.д.).

Во-вторых, герменевтическая парадигма перевода открыта для новых моделей, которые на практике докажут свою состоятельность.

В-третьих, благодаря открытости герменевтическая парадигма перевода исторически устойчива, ибо отвечает современной тенденции глобализации и интеграции научного знания.

В-четвертых, глобализация и интеграция теоретико-методологического переводоведческого знания подразумевают трансдисциплинарный подход к проблемам переводоведения, который обозначается и детально анализируется в 6-й главе монографии. Автор не просто призывает научное сообщество присоединиться к мнению А. Лешнера о том, что «монодисциплинарная наука умерла. Ее больше нет!» (Johansson 2004; Йоханссон 2008: 33), но и усматривает исторические предпосылки появления тенденции привлечения данных нескольких дисциплин к решению переводческих задач в отечественной транслатологии в статье Р. Якобсона «Лингвистические аспекты перевода». В ней крупнейший лингвист XX века рекомендует (согласно завету Дионисия Ареопагита) «главное внимание уделять когнитивным ценностям.., а не словам самим по себе» (Якобсон 1978: 17). Автор монографии приходит к выводу о том, что для преодоления «существенных трудностей перевода разностилевых и разножанровых текстов Р. Якобсон волейневолей подталкивает современных переводчиков на оптимальные междисциплинарные модели» (Мишкуров 2018: 167).

При диахроническом и синхроническом освещении затронутой проблемы Э.Н. Мишкуров проводит четкую границу между понятиями «междисциплинарность» и «трансдисциплинарность». Если первый термин подразумевает наличие ведущей и ведомых дисциплин, то второй означает холистический подход к изучению «предмета без резко очерченных границ между задействованными дисциплинами» (Мишкуров 2018: 183).

В-пятых, трансдисциплинарность в переводоведении становится возможной при учете особой роли философской герменевтики, что отражено автором в названии парадигмы. Ученый доказывает, что «герменевтика не идет в ряду дисциплин - антропологии, социологии, семиотики, культурологии, психологии и др., обслуживающих науку о переводе, а являет собой наддисциплинарную теоретикометодологическую матрицу в виде „герменевтического методологического стандарта“" и упорядочивающего применение более двадцати смежных наук в переводческом процессе» (Мишкуров 2018: 180).

Герменевтический поворот в западно-европейском переводоведении произошел на несколько десятилетий раньше, чем в отечественном. В монографии детально излагаются причины «подобного застоя», динамика развития герменевтического влияния на перевод и обосновывается современное состояние транслатологии от «герменевтической усталости» на Западе до исходной позиции в России. Импонирует не описательный, а критический подход к оценке взглядов Хайдеггера, Гадамера, Беньямина, Деррида и др. на переводоведение. 
Например, автор избирает оригинальную методику анализа эссе В. Беньямина «Die Aufgabe des Übersetzers» («Задача переводчика»). Как известно, для немецкого философа идеал текста состоял исключительно из цитат, которые бы «сами иллюстрировали друг друга и были способны отстоять свое право на существование именно в таком, свободно плавающем виде» (Грицанов 2007: 48-49; Арендт 2003: 7). Данная «цитатная методика» позволила Э.Н. Мишкурову не только проиллюстрировать сущность идей о переводе В. Беньямина, взгляды его сторонников («создание единого языка (т.е. „чистого языка“ - Э.М.) обозначает достижение взаимопонимания, которое осуществляется в переводе, если избежать двух крайностей: понимать только автора или понимать только себя» (Богатырева 2007: 8) и оппонентов (заявленные в работе Беньямина постулаты «принесли в переводческую среду не столько мир и согласие, сколько меч и раздор» (Чубаров 2011: 251-252), но и высказать собственное мнение о целесообразности избирательного подхода к работам философов, с сохранением в герменевтической методологии «работающих» приемов и опущением «мистико-поэтических» пассажей. «Вряд ли нам стоит безоглядно принимать конкретную рекомендацию Н.С. Автономовой - следовать сразу за всеми „философскими звездами“ на переводоведческом небосклоне, в том числе „вслед за Беньямином, Рикером или Деррида, за многими другими“». Весьма опасно совмещать несовместимое - однозначное неприятие Рикером идей Беньямина или совмещение его плодотворной идеи о «языковом гостеприимстве» со схоластическими рассуждениями Деррида об «оригинале, вопиющем и молящем о переводе» (Мишкуров 2018: 39—40).

Автор монографии искусно подводит читателей к выводу о том, что великие философы подходили к переводу как к философскому тексту, т.е. анализ процесса перевода заканчивался интерпретацией, но специфика переводоведческого процесса при этом несколько размывалась.

Данную существенную проблему Э.Н. Мишкурову удалось успешно решить при создании герменевтико-переводческого методологического стандарта (ГПМС). И наконец, таким образом, герменевтическая парадигма перевода ставит точку в спорах о признании переводоведения самостоятельной наукой, ибо наиболее распространенным аргументом противников обособления транслатологии в отдельную дисциплину было утверждение об отсутствии у данной науки собственной парадигмы.

Итак, для герменевтической парадигмы перевода Э.Н. Мишкуровым был создан инновационный «герменевтико-переводческий методологический стандарт» (ГПМС), представляющий собой четырехступенчатую матрицу, включающую в себя этапы предпонимания, понимания, интерпретации и переводческого решения. Как видим, ГПМС основывается на герменевтическом стандарте, и не случайно. Герменевтику и транслатологию объединяет предмет исследования текст, как знаково-символическая система, требующая декодирования для извлечения системы смыслов. Однако если для герменевтики достаточно всесторонне проанализировать текст в условиях одноязычной ситуации, то для переводоведения необходимо не просто вывести систему текстовых смыслов оригинала, но и передать ее в тексте перевода. Наличие двуязычной ситуации требует рассмотрения этапов предпонимания, понимания и интерпретации герменевтиче- 
ского стандарта в переводоведческом ключе и добавления этапа принятия переводческого решения. Кратко охарактеризуем каждый из этапов.

Этап предпонимания (предзнания, предпознания) представляет собой трансдисциплинарный предпереводческий анализ текста оригинала с целью установления информации экстралингвистического и собственно лингвистического характера, необходимой и достаточной для выведения системы текстовых смыслов. Другими словами, предпонимание - это «расширенный трансдисциплинарный анализ исходного текста с целью перехода к более развернутой части переводческого процесса — к стадии понимания ИТ. С помощью предпонимания устанавливаются оптимальные „горизонты понимания“, т.е. степень осмысления глубин и границ проникновения в ИТ» (Мишкуров 2018: 196).

Под этапом понимания автор монографии усматривает использование ряда специальных методик анализа и осмысления исходного текста, ведущих к глубокому пониманию системы текстовых смыслов. Данный вид деятельности является подготовительным для иноязычной интерпретации.

Отметим, что вызывает научный интерес переведение философской проблемы «герменевтического круга» в феномен «герменевтической спирали». Однако понимание в ГПМС не является открытым процессом. Своеобразным выводом служит высказывание Гадамера: «тот, кто переводит <..> не может оставить в своем переводе ничего такого, что не было бы ясным ему самому» (Гадамер 1988: 449; Мишкуров 2018: 196).

Третий этап ГПМС - это «герменевтическая душа перевода» — интерпретация. Автор определяет ее как «особый вид деятельности переводчика по выбору стратегии движения переводческой рефлексии «от автора к читателю / от читателя к автору», или в других терминах — по выбору стратегии «форенизация»/«доместикация». Вместе с тем он осуществляет перебор вариантов перевода функционально-закономерных соответствий, ищет пути преодоления «непереводимого» доступными способами переложения, порождает исходно «черновой» вариант текста, который будет служить основой для принятия окончательного переводческого решения.

Не исключено, что в ходе интерпретации у переводчика происходит сложение инвариантного рабочего «промежуточного иноязыка», рефлексивно-интуитивно настраиваемого переводчиком на формирование первичных вариантов образа будущего итогового языка перевода, отчуждаемого для реципиента» (Мишкуров 2018: 233).

Если философско-герменевтический методологический стандарт оканчивается этапом интерпретации, то ГПМС, учитывая специфику дву-/полиязычной ситуации переводческой деятельности, включает в себя стадию принятия переводческого решения. Основу переводческого решения составляет уподобление транслята оригиналу. Данный этап, по сути, является порождением «окончательного результирующего „дискурсивно-эквивалентного / прагматически адекватного“ переводного текста, отчуждаемого в сферу читательской рефлексии» (Мишкуров 2018: 269).

Добавим, что между стадиями ГПМС нет «строгого» разделения, они находятся в отношениях взаимосвязи и взаимодополнения. 
Говоря об общем взгляде автора монографии на сущность понятия «перевод», отметим, что в исследовании развивается идея Ж.Р. Ладмираля (Ladmiral 1994) о переходе «перевода» из «науки-знания» в «науку-рефлексию».

Несомненный научный интерес вызовут рассмотренные в монографии проблемы плюральности перевода, триады автор - переводчик - читатель, роли подстрочника в переводческой деятельности и многие другие.

Теоретические положения иллюстрируются оригинальными примерами из художественных произведений отечественных и зарубежных авторов.

Текст монографии стилистически выдержан, написан научным, но доступным языком, временам автор допускает иронические замечания, что не оставит читателя равнодушным.

Исследование предназначено для широкого круга специалистов в области переводоведения, философии, студентов лингвистических университетов и всех тех, кто интересуется проблемами перевода.

М.Г. Новикова, 2019

\section{СПИСОК ЛИТЕРАТУРЫ / REFERENCES}

Арендт Х. Вальтер Беньямин. Люди в темные времена. М.: МШПИ, 2003. [Arendt, Н. (2003). Val'ter Ben'yamin. Lyudi v temnye vremena. (People in Dark Times) Moscow: MSHPI. (In Russ.)].

Богатырева Е.Д. Художественный перевод как интерпретация (на материале французских переводов поэмы А.С. Пушкина «Медный всадник»): автореф. дис. ... к.ф.н. М., 2007. [Bogatyreva, E.D. (2007). Hudozhestvennyj perevod kak interpretaciya (na materiale francuzskih perevodov poehmy A.S. Pushkina «Mednyj vsadnik») (Literary Translation as Interpretation (on the Material of the French Translations of the Poem by A.S. Pushkin "The Bronze Horseman"). Moscow. (In Russ.)].

Гадамер Х-Г. Истина и метод: Основы философской герменевтики / пер. с нем. М.: Прогресс, 1988. [Gadamer, H-G. (1988). Istina i metod: Osnovy filosofskoj germenevtiki (Truth and Method: Basics of Philosophical Hermeneutics). Moscow: Progress. (In Russ).].

Йоханссон Ф. Эффект Медичи: возникновение инноваций на стыке идей, концепций и культур. М.: Вильямс, 2008. [Johansson, F. (2008). The Medici Effect: Breakthrough insights at the intersection of ideas, concepts, and cultures. Moscow: Vil'yams. (In Russ.)].

Комиссаров В.Н. Теория перевода (лингвистические аспекты). Учеб. для ин-тов и фак. иностр. яз. М.: ВШ, 1990. [Komissarov, V.N. (1990). Teoriya perevoda (lingvisticheskie aspekty). (Theory of Translation (Linguistic Aspects).Ucheb. dlya in-tov i fak. inostr. yaz. Moscow: VSH. (In Russ.)].

Кун Т. Структура научных революций. М.: Прогресс, 1977. [Kun, Т. (1977). Struktura nauchnyh revolyucij. (Structure of Scientific Revolutions) Moscow: Progress. (In Russ.)].

Мишкуров Э.Н. Герменевтика перевода (теоретико-методологический стандарт). Монография. M.: Воен. ун-т, 2018. [Mishkurov, EH.N. (2018). Germenevtika perevoda (teoretiko-metodologicheskij standart). (Hermeneutics Translation (Theoretico-methodological Standard). Monografiya. Moscow: Voen. un-t (In Russ.)].

Рецкер Я.И. Теория перевода и переводческая практика. Очерки лингвистической теории перевода / Доп. и комм. Д.И. Ермоловича. 5-е изд., испр. и доп. М.: Аудитория, 2016. [Recker, YA.I. (2016). Teoriya perevoda i perevodcheskaya praktika. Ocherki lingvisticheskoj teorii perevoda (Theory of Translation and Translation Practice. Essays on Linguistic Translation Theory). 5-th ed. Moscow: Auditoriya (In Russ.)]. 
Фесенко Т.А. Лингвоментальная модель процесса перевода // Язык, сознание, коммуникация: Сб. статей / Отв. ред. В.В. Красных, А.И. Изотов. М.: МАКС Пресс, 2001. Вып. 20. C. 58-62. [Fesenko, T.A. (2001). Linguistic Model of the Translation Process. Language, Consciousness, Communication, 20, 58 - 62 (In Russ.)].

Хомутова Т.Н. Научные парадигмы в лингвистике // Вестник Челябинского государственного университета. 2009. № 35 (173) Филология. Искусствоведение. Вып. 37. С. 142-151. [Homutova, T.N. (2009) Scientific Paradigms in Linguistics // Bulletin of Chelyabinsk State University. Philology. Art History, 37, 142-151 (In Russ.)].

Чубаров И.М. Перевод как опыт нечувственных уподоблений. Причины неудач переводов «Задачи переводчика» В. Беньямина на русский язык // Логос. 2011. № 5-6. С. 237-252. [Chubarov, I.M. (2011). Translation as Experience of Insensible Assimilations. Reasons for Failure of Translation of "Translator's Tasks" by V. Benyamin into Russian. Logos Journal, 5-6, 237-252 (In Russ.)].

Швейцер А.Д. Теория перевода. Статус, проблемы, аспекты. М.: Наука, 1988. [Shvejcer, A.D. (1988). Teoriya perevoda. Status, problemy, aspekty. (Translation Theory. Status, Problems, Aspects). Moscow: Nauka (In Russ.)].

Якобсон Р. О лингвистических аспектах перевода // Вопросы теории перевода в зарубежной лингвистике. Сб. статей. М.: Междунар. отношения, 1978. С.16-24. [Yakobson, R. (1978). On Linguistic Aspects of Translation. Questions of Translation Theory in Foreign Linguistics, Digest of Articles, 16-24 (In Russ.)].

Even-Zohar, Itamar (1990). "Polysystem Theory", in Polysystem Studies, [= Poetics Today 11:1], $9-26$.

Johansson, F. (2004). The Medici Effect: Breakthrough insights at the intersection of ideas, concepts, and cultures. Harvard Business School Press.

Ladmiral, J.-R. (1994). Traduire: théorèmes pour la traduction. Paris: Gallimard.

Nida, E. (1964). Towards a Science of Translating. Special Reference to Principles and Procedures Involved in Bible Translating. Leiden

\section{Словари / Dictionaries}

Грицанов А.А. Беньямин Вальтер // Новейший философский словарь. Постмодернизм. Минск: Совр. литератор, 2007. [Gricanov, А.A. (2007). Ben'yamin Val'ter // Novejshij filosofskij slovar'. Postmodernizm. Minsk: Sovr. literator. (In Russ)]

\section{Сведения об авторе:}

МАРИНА ГЕННАДЬЕВНА НОВИКОВА - докТор филологических наук, доцент, Российский государственный университет правосудия, профессор кафедры иностранных языков. Сфера научных интересов: переводоведение, лингвосемиотика, когнитивная лингвистика, герменевтика, философия.

Контактная информация: e-mail: novikova_mg@mail.ru

\section{Bionote:}

MARINA G. NOVIKOVA is Dr., Professor at the Department of Modern Languages at Russian State University of Justice. Her research interests include Translation Studies, Linguosemiotics, Cognitive Linguistics, Hermeneutics and Philosophy.

Contact information: e-mail: novikova_mg@mail.ru 